\title{
Distribución de competencias en turismo en los Estados Partes del MERCOSUR
}

\section{Distribution of competences in tourism in the States Parties of MERCOSUR}

ARTÍCULO

\section{Eugenio del Busto}

Universidad Nacional de Quilmes. Contacto: edelb@uvq.edu.ar

\section{Resumen}

El presente artículo analiza el sistema constitucional de distribución de competencias y sus implicancias en el turismo en los países de América Latina que integran, en carácter de Estados Parte, el MERCOSUR. La finalidad es conocer las potestades de los entes que intervienen en la regulación de la actividad.

Se concluye en la importancia de afianzar los procesos de integración en materia turística, con el objeto de cooperar en su desarrollo de manera sustentable. Para ello se propicia la armonización de la normativa, respetando las potestades que emanan de los diferentes sistemas de distribución de competencias.

Palabras clave: Derecho; Turismo; Derecho del turismo; Distribución de competencias en turismo; MERCOSUR.

\section{Abstract}

This paper analyzes the system of constitutional distribution of competencies and its implications in tourism, in the countries of Latin America that integrate, as States Parties, the MERCOSUR, with the purpose of knowing the powers of the entities involved in the regulation of the activity.

The paper concludes with some observations regarding the importance of strengthening the integration's processes in tourism, in order to cooperate in their development in a sustainable manner. To this end, the harmonization of regulations is encouraged, respecting the powers that arise from the different systems of distribution of competences.

Keywords: Law; Tourism; Travel law; Distribution of competencies in tourism; MERCOSUR.

\section{Introducción}

El turismo es una actividad que por su propia naturaleza "trasciende a las naciones que lo originan, a las que lo reciben y a su propio desarrollo" (Santana, 2008, p. 9). Por sus características excede el ámbito interno de los Estados para conectarse con las relaciones internacionales, donde genera un sinnúmero de transacciones entre los Estados: "[...] visas, integración turística regional, circuitos, promoción regional conjunta, atracción de inversiones turísticas, cooperación internacional para la asistencia técnica y capacitación, 
créditos al desarrollo turístico, declaraciones internacionales de bienes patrimoniales, normas y acuerdos turísticos internacionales, divisas, etc." (González del Miño, 2012, p. 46). Es además, una actividad que presenta "un grado positivo a la cooperación internacional tanto en el ámbito público como privado". (Montaner Montejano, 2002, p.79).

Estas circunstancias han sido advertidas por los Estados y han dado lugar a que las naciones que cuentan con intereses comunes en materia turística, superen sus fronteras para promover su fortalecimiento en conjunto y otorgar a la actividad un desarrollo sustentable.

En el ámbito Latinoamericano así lo ha puesto de manifiesto el Compromiso del Cuzco, alcanzado en la I Reunión Iberoamericana de Ministros de Turismo, realizada el 7 de septiembre de 2001, por el cual se impulsa un espacio iberoamericano para el turismo y se coincide en la necesidad de consolidar el potencial del turismo, fortaleciendo los lazos de unión de los países iberoamericanos y la solidaridad entre nuestros pueblos.

Por su parte, en el marco del Mercosur, con la creación de la Reunión Especializada de Turismo de los Estados Partes -a través de la Resolución MERCOSUR/GMC/RES № 12/91, del Grupo Mercado Común- y que tiene como función proponer al Grupo Mercado Común medidas tendientes a coordinar sus respectivas políticas turísticas, se reconoce la trascendencia de la actividad, al afirmar "la notoria vinculación e importancia del turismo en relación a los objetivos del Tratado de Asunción".

El alcance de esos logros exige, además de la voluntad política manifiesta, tener en cuenta, entre otros, los aspectos jurídicos involucrados, procurando armonizar las respectivas legislaciones.

El presente artículo se enmarca en el Programa Dimensiones y alcances del desarrollo territorial, que integra el Proyecto Desarrollo del turismo en países de América Latina. Análisis comparado y estadios de avances de la Universidad Nacional de Quilmes - Departamento de Economía y Administración -, en el que participa el autor como investigador.

El objetivo que persigue es indagar acerca de los fundamentos jurídicoconstitucionales en los que se basan, en cada uno de los Estados analizados, las potestades de los entes que intervienen en la regulación de la actividad turística, a fin de conocer la factibilidad para la armonización de la normativa en la materia, evitando se invadan competencias que corresponden a entes específicos.

Para ello se aborda el análisis de las normas constitucionales, de los Estados parte del MERCOSUR, que se encargan de distribuir competencias en materia turística y en otras con incidencia en aquella, en las que se encuentra la fuente para el dictado de su normativa. 


\section{Los Estados Partes del Mercosur}

El Tratado de Asunción, suscripto el 26 de marzo de 1991 por Argentina, Brasil, Paraguay y Uruguay, da origen al MERCOSUR o Mercado Común del Sur. El MERCOSUR, de acuerdo con Comas (2012, p. 93): "es un proceso integracionista que en una primera etapa se centró en la visión comercial y en los últimos años comenzó a acentuar la integración política y social y tuvo avances significativos en el plano institucional...".

El enunciado Tratado determina en su Preámbulo, así como en el artículo 1, los objetivos perseguidos, a saber: la ampliación de las actuales dimensiones de sus mercados nacionales, para acelerar sus procesos de desarrollo económico con justicia social; mediante el más eficaz aprovechamiento de los recursos disponibles, la preservación del medio ambiente, el mejoramiento de las interconexiones físicas, la coordinación de las políticas macroeconómicas y la complementación de los diferentes sectores de la economía, con base en los principios de gradualidad, flexibilidad y equilibrio. Ello implica: la libre circulación de bienes, servicios y factores productivos entre los países; el establecimiento de un arancel externo común y la adopción de una política comercial común; la coordinación de políticas macroeconómicas y sectoriales entre los Estados Partes y el compromiso de armonizar sus legislaciones en las áreas pertinentes, para lograr el fortalecimiento del proceso de integración.

La República Argentina, la República Federativa del Brasil, la República del Paraguay y la República Oriental del Uruguay, revisten, en su carácter de signatarios del Tratado de Asunción, la condición de Estados Partes del MERCOSUR.

La República Bolivariana de Venezuela se ha incorporado como Estado Parte del MERCOSUR, a partir de la entrada en vigencia del Protocolo de Adhesión República Bolivariana de Venezuela, suscripto el 4 de Julio de 2006 por los signatarios del Tratado de Asunción y Venezuela. A partir de la vigencia de la Decisión sobre la suspensión de la República Bolivariana de Venezuela en el MERCOSUR en aplicación del Protocolo de Ushuaia sobre compromiso democrático en el MERCOSUR, suscripta el 5 de agosto de 2017, por Argentina, Brasil, Paraguay y Uruguay, aquella se encuentra suspendida en todos los derechos y obligaciones inherentes a su condición de Estado Parte.

El Estado Plurinacional de Bolivia se encuentra en proceso de incorporación como Estado Parte del MERCOSUR, y adquirirá tal condición una vez se produzca la entrada en vigencia del Protocolo de Adhesión del Estado Plurinacional de Bolivia al MERCOSUR, suscripto el 17 de julio de 2015, por Argentina, Bolivia, Brasil, Paraguay y Uruguay. El Protocolo surtirá efecto a partir del trigésimo día contado desde la fecha del depósito del 
último instrumento de ratificación del mismo por parte de los Parlamentos de todos los Estados que suscribieran el Protocolo. ${ }^{1}$

\section{Conceptualización de la distribución de competencias}

Previo a todo análisis, es menester aclarar, para este trabajo, el concepto de distribución de competencias que indica, de manera genérica, el reparto de las potestades o funciones de legislación, ejecución y jurisdicción, en cada una de las personas públicas o sus órganos, de una materia determinada.

Al respecto de la potestad o función, el jurista argentino Esain (2004) señala:

Si queremos indagar sobre como se distribuyen las competencias en un sistema federal, una buena forma de iniciar la investigación será verificar los conceptos de función y materia. Porque el ejercicio de una competencia concurrente se lo puede entender como la asunción por parte de uno o varios Entes territoriales de una serie de funciones sobre una materia determinada. Estas funciones son fundamentalmente la función de normar la materia en cuestión, la función de ejecutar lo que previamente ha sido normado y la función de dirimir conflictos que se presenten aplicando las normas generales de esa materia para elaborar normas individuales (en el sentido Kelseniano de los términos) sentenciando. La función de normar se refiere - en un sentido amplio - a la regulación jurídica de la materia en toda su extensión, ya sea a través de instrumentos normativos de rango legal o reglamentario. La función ejecutiva, en cambio está vinculada con la puesta en marcha de aquello que ha sido regulado por la norma. Generalmente ésta función se lleva a cabo a través de la actuación de la administración (reglamentos ejecutivos y actos administrativos individuales) pero además puede que en algunos casos también ésta función sea cumplida por la legislatura a través de las denominadas leyes programa o leyes planes, o leyes medida. La función Judicial implica dirimir conflictos individuales y está vinculada a la actuación ante los tribunales de justicia, para obtener la resolución que restablezca el derecho violado o dañado (p. 778).

La competencia puede ser definida, entonces, como "la titularidad de una potestad o función pública sobre una materia por un determinado ente público" (Blasco, 1981, p. 311). En tanto que la materia, según el Tribunal Constitucional Español "se puede concebir como aquel conjunto de actividades, bienes o institutos jurídicos referentes a cierto sector homogéneo" (STC 123/1984). Ello permite afirmar a Álvarez Conde (2008, p. 577) que "la materia es el objeto de la competencia" y la potestad o función "el contenido de dicha titularidad".

La doctrina en Latinoamérica también se ha encargado de elaborar una definición de competencia, para el administrativista argentino Gordillo (2012, XII-9) puede conceptualizarse como "el conjunto de actividades que el órgano puede legítimamente realizar". En tanto que para el constitucionalista Bidart Campos (2005):

La competencia es la asignación de "su" función a un órgano-institución. El uso del poder "fuera" de la competencia provoca exceso o abuso de poder; y el uso del poder 
"dentro" de la competencia, pero con un "fin" distinto, la desviación de poder. En el derecho constitucional del poder, la incompetencia es la regla y la competencia la excepción (p. 11).

Pérez Guerra y Ceballos Martín (2009) han resaltado la importancia de la competencia al afirmar que: "Poseer la titularidad de la competencia sobre una determinada materia supone el poder actuar legislando, gestionando, controlando sobre un determinado sector de la vida económica o social de una comunidad" (p. 459).

La delimitación precisa de las competencias sobre las diferentes materias y su configuración como ámbitos exclusivos tiene trascendencia en el orden jurídico-práctico, entre otros aspectos resaltados por Viver Pi Sunyer (1989), porque:

- Constituye una ayuda para los legisladores y los poderes públicos a la hora de resolver la cuestión de precisar el alcance material de las competencias.

- La delimitación favorece un funcionamiento armónico de los entes territoriales estatales, evitando solapamientos y reduciendo los conflictos constitucionales de competencias.

- Favorece una mayor previsibilidad y continuidad de la jurisprudencia.

La trascendencia que cobra la determinación de las competencias, es clara, no solo desde el punto de vista de la correcta distribución de potestades entre los diferentes entes estatales, sino también desde la perspectiva del administrado, que se ve sometido a ellas.

\section{Distribución de competencias en materia turística en los Estados Partes del MERCOSUR}

La doctrina española, según Guillén Galindo (1999), ha considerado al turismo como una materia inter y multidisciplinar, ya que se encuentra afectada por otro tipo de materias: ordenamiento del territorio y planeamiento, urbanística, protección del patrimonio cultural y natural, transportes y comunicaciones, ocio y deportes, etcétera. De ahí que el análisis del subsistema jurídico que le es aplicable es complejo, pero imprescindible para la indagación de cualquier Política Turística común, ya que aquella implica la necesidad de conocer la normativa que la sustenta, es decir el conocimiento de los instrumentos legales que la soportan (Peña Miranda, 2009).

El caso de los países analizados en América Latina no es diferente y a la complejidad antes enunciada corresponde adicionar que la materia turística no siempre encuentra recepción expresa en sus constituciones. Por otra parte, cuando existe tal referencia puede no tratarse de un precepto en el que se distribuyen competencias. En cualquier circunstancia no puede dejar de afirmarse que el fundamento para el reparto de 
competencias en materia turística, con carácter general, y para la regulación de los diferentes subsectores que la conforman, debe encontrarse en aquellas.

Sostiene Güidi (2014), en una afirmación hecha para la República Argentina pero que puede ser de utilidad para el resto de las normas constitucionales de los países estudiados, que:

existe una fuerte vinculación del turismo con las normas constitucionales ya que, tanto las disposiciones incluidas en la parte dogmática de la norma fundamental como las referidas a la distribución de competencias entre la Nación y las provincias constituyen el fundamento y razón de las disposiciones legislativas y reglamentarias que se aplican a la actividad (p. 805).

De ahí que se considere que los parámetros para definir las atribuciones de la nación y las diferentes unidades territoriales que adopta cada Estado en relación al turismo se encuentran esbozados en la Carta Magna (del Busto, 2009). De esta manera es factible encontrar diferentes preceptos en las constituciones de los países analizados que distribuyen competencias en turismo y otros que otorgan potestades que impactan sobre aquel.

El carácter transversal del turismo, por su parte, hace que se relacione a un cúmulo de actividades con las que su interacción presenta una mayor o menor vinculación. Esta circunstancia se ve reflejada cuando se realiza su análisis desde la perspectiva jurídica, ya que, si bien existen competencias directas sobre la materia, hay otras que con un carácter más general impactan respecto de la misma, aunque también lo hacen con relación a otras actividades económicas. De ahí que intentar una clasificación jurídica ajustada a una realidad tan cambiante e interrelacionada con otras materias, puede en ocasiones resultar una tarea difícil de acometer.

En los casos de estudio elegidos se han distinguido los diferentes estamentos territoriales, así como los poderes correspondientes, siguiendo el orden enunciado en cada una de las Constituciones analizadas, de manera tal que pueden encontrarse, sin distinción, competencias que directamente operan sobre la actividad turística como otras que tienen una incidencia tal que no pueden dejar de enunciarse.

No cabe duda que existen otras competencias no enunciadas que pueden considerarse cuando se realiza un estudio respecto de su impacto con relación al turismo, por lo que se considera que esta clasificación se encuentra abierta a nuevos aportes.

\section{IV.1. Distribución de competencias en materia turística en la República Argentina}

La Constitución Nacional vigente en la República Argentina (en adelante CN), fue sancionada el $1^{\circ}$ de mayo de 1853 y reformada en los años 1860, 1866, 1898, 1957 y 1994. La CN adopta la forma representativa, republicana y federal (artículo $1^{\circ}$ de la CN). 
De acuerdo con Bidart Campos (2005) “...desde la reforma de 1994 la dualidad de estado federal y provincias muestra un rostro parcialmente nuevo, porque aparecen las menciones expresas a los municipios provinciales y a la ciudad de Buenos Aires, esta última con un sujeto de la relación Federal" (p. 38).

La CN no contiene una disposición expresa respecto al turismo y por tanto tampoco acerca de la distribución de competencias en la materia, pero puede sostenerse, sin embargo que las disposiciones que de ella emanan determinan las competencias de los diferentes entes que intervienen en la actividad (del Busto, 2014). Lo que antecede permite perfilar un marco normativo complejo, con diversidad de potestades distribuidas conforme se refleja en la Tabla siguiente.

Tabla № 1. Competencias en materia turística en la República Argentina

\begin{tabular}{|c|c|}
\hline Gobierno & poner contribuciones a la población (artículo 4, CN). \\
\hline Federal & $\begin{array}{l}\text { Reglamentar el ejercicio de los derechos de trabajar y ejercer toda industria } \\
\text { lícita, de navegar y comerciar, de entrar, permanecer, transitar y salir del } \\
\text { territorio argentino, de usar y disponer de su propiedad y de enseñar y } \\
\text { aprender (artículo } 14, \mathrm{CN} \text { ). }\end{array}$ \\
\hline & $\begin{array}{l}\text { Reglamentar la libertad de navegación de los ríos interiores de la Nación } \\
\text { para todas las banderas (artículo } 26, \mathrm{CN} \text { ). }\end{array}$ \\
\hline & $\begin{array}{l}\text { Afianzar las relaciones de paz y comercio con las potencias extranjeras, } \\
\text { mediante tratados que estén en conformidad con los principios de derecho } \\
\text { público establecidos en la Constitución (artículo } 27, \mathrm{CN} \text { ). }\end{array}$ \\
\hline & $\begin{array}{l}\text { Reglamentar el derecho a un ambiente sano, equilibrado, apto para el } \\
\text { desarrollo humano y para que las actividades productivas satisfagan las } \\
\text { necesidades presentes sin comprometer las de las generaciones futuras, y a } \\
\text { la utilización racional de los recursos naturales, a la preservación del } \\
\text { patrimonio natural y cultural y de la diversidad biológica, y a la información y } \\
\text { educación ambientales, dictar las normas que contengan los presupuestos } \\
\text { mínimos de protección, y a las provincias, las necesarias para } \\
\text { complementarlas, sin que aquéllas alteren las jurisdicciones locales (artículo } \\
41, \mathrm{CN} \text { ). }\end{array}$ \\
\hline & $\begin{array}{l}\text { Proveer a la protección de los derechos de los consumidores y usuarios, a la } \\
\text { educación para el consumo, a la defensa de la competencia contra toda } \\
\text { forma de distorsión de los mercados, al control de los monopolios naturales y } \\
\text { legales (artículo } 42, \mathrm{CN} \text { ). }\end{array}$ \\
\hline $\begin{array}{l}\text { Congreso de } \\
\text { la Nación }\end{array}$ & $\begin{array}{l}\text { Establecer los derechos de importación y exportación, uniformes en toda la } \\
\text { Nación (inciso 1); Imponer contribuciones indirectas como facultad } \\
\text { concurrente con las provincias. Imponer contribuciones directas, por tiempo } \\
\text { determinado, proporcionalmente iguales en todo el territorio de la Nación, }\end{array}$ \\
\hline
\end{tabular}




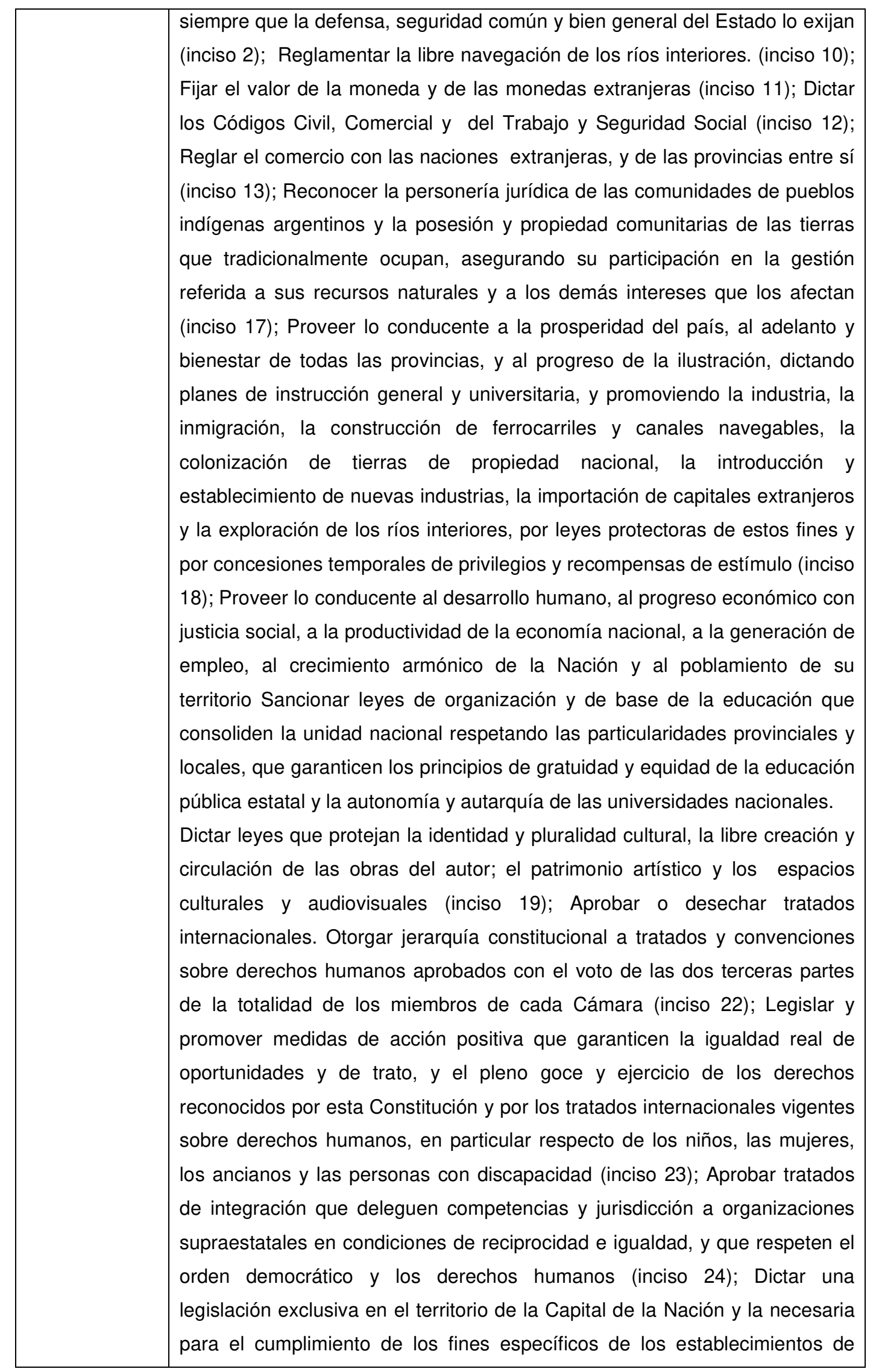




\begin{tabular}{|c|c|}
\hline & $\begin{array}{l}\text { utilidad nacional en el territorio de la República (inciso } 30 \text { ); Hacer todas las } \\
\text { leyes y reglamentos que sean convenientes para poner en ejercicio los } \\
\text { poderes antecedentes, y todos los otros concedidos al Gobierno de la } \\
\text { Nación Argentina (inciso } 32 \text { ) (artículo } 75, \mathrm{CN} \text { ). }\end{array}$ \\
\hline \multirow[t]{2}{*}{$\begin{array}{l}\text { Presidente de } \\
\text { la Nación }\end{array}$} & $\begin{array}{l}\text { Dictar Decretos en uso de Delegación legislativa por parte del Congreso de } \\
\text { la Nación, en materia de administración o de emergencia pública (artículo } 76 \text {, } \\
\mathrm{CN} \text { ). }\end{array}$ \\
\hline & $\begin{array}{l}\text { Dictar reglamentos para la administración general del país (inciso 1); Expedir } \\
\text { las instrucciones y reglamentos que sean necesarios para la ejecución de las } \\
\text { leyes de la Nación (inciso 2); Participar de la formación de las leyes con } \\
\text { arreglo a la Constitución, promulgar y hacer publicar y dictar Decretos por } \\
\text { razones de Necesidad y Urgencia (inciso 3); Concluir y firmar tratados y } \\
\text { otras negociaciones requeridas para el mantenimiento de buenas relaciones } \\
\text { con las organizaciones internacionales y las naciones extranjeras (inciso 11) } \\
\text { (artículo 99, CN). }\end{array}$ \\
\hline $\begin{array}{ll}\text { Jefe } & \text { de } \\
\text { Gabinete } & \text { de } \\
\text { Ministros } & \end{array}$ & $\begin{array}{l}\text { Ejercer la administración general del país (inciso 1); efectuar los } \\
\text { nombramientos de los empleados de la Administración (inciso 3); hacer } \\
\text { recaudar las rentas de la Nación y ejecutar la Ley de Presupuesto Nacional } \\
\text { (inciso 7); Refrendar los decretos reglamentarios de las leyes (inciso 8) } \\
\text { (artículo 100, CN). }\end{array}$ \\
\hline Ministros & $\begin{array}{l}\text { Tomar resoluciones concernientes al régimen económico y administrativo de } \\
\text { sus respectivos departamentos (artículo 103, CN). }\end{array}$ \\
\hline \multirow[t]{8}{*}{$\begin{array}{l}\text { Gobiernos de } \\
\text { Provincia }\end{array}$} & $\begin{array}{l}\text { Complementar las normas de presupuestos mínimos en materia de ambiente } \\
\text { (artículo } 41, \mathrm{CN} \text { ). }\end{array}$ \\
\hline & Tutelar los derechos de usuarios y consumidores (artículo 42, CN). \\
\hline & Crear impuestos provinciales (artículo 75, inciso 2). \\
\hline & $\begin{array}{l}\text { Ejercer el poder de policía y las potestades tributarias en establecimientos de } \\
\text { utilidad nacional (artículo } 75 \text {, inciso } 30, \mathrm{CN} \text { ). }\end{array}$ \\
\hline & Conservar todo el poder no delegado al Gobierno federal (artículo 121, CN). \\
\hline & $\begin{array}{l}\text { Dictar su propia Constitución asegurando la autonomía municipal y reglando } \\
\text { su alcance y contenido en el orden institucional, político, administrativo, } \\
\text { económico y financiero (artículo } 123, \mathrm{CN} \text { ). }\end{array}$ \\
\hline & $\begin{array}{l}\text { Celebrar convenios internacionales, crear regiones para el desarrollo } \\
\text { económico-social y establecer órganos con facultades para el cumplimiento } \\
\text { de sus fines y administrar los recursos naturales (artículo 124). }\end{array}$ \\
\hline & $\begin{array}{l}\text { Promover su industria, la inmigración, la construcción de ferrocarriles y } \\
\text { canales de navegables, la colonización de tierras de propiedad provincial, la } \\
\text { introducción y establecimiento de nuevas industrias, la importación de } \\
\text { capitales extranjeros y la exploración de sus ríos, por leyes protectoras de } \\
\text { estos fines, y con sus recursos propios (artículo } 125, \mathrm{CN} \text { ). }\end{array}$ \\
\hline
\end{tabular}




\begin{tabular}{|l|l|}
\hline Municipios & $\begin{array}{l}\text { Tutelar los derechos de usuarios y consumidores en sus ámbitos territoriales } \\
\text { (artículo 42, CN). }\end{array}$ \\
\cline { 2 - 2 } & $\begin{array}{l}\text { Ejercer el poder de policía y las potestades tributarias en establecimientos de } \\
\text { utilidad nacional (artículo 75, inciso 30, CN). }\end{array}$ \\
\cline { 2 - 3 } & $\begin{array}{l}\text { Dictar normas en uso de las potestades emanadas de las Constituciones } \\
\text { provinciales (artículo 123, CN). }\end{array}$ \\
\hline $\begin{array}{l}\text { Ciudad } \\
\text { Autónoma de } \\
\text { Buenos Aires }\end{array}$ & $\begin{array}{l}\text { Ejercer las potestades de legislación en el marco del régimen de autonomía } \\
\text { establecido (artículo 129). }\end{array}$ \\
\hline
\end{tabular}

Fuente: Elaboración propia

IV.2. Distribución de competencias en materia turística en la República Federativa del Brasil

La Constitución vigente de la República Federativa de Brasil (en adelante CRFB), sancionada el 5 de octubre de 1988, presenta 99 (noventa y nueve) Enmiendas Constitucionales y 6 (seis) Enmiendas Constitucionales de Revisión. La CRFB constituye un Estado democrático de derecho (artículo 1 CRFB), que adopta, a partir de lo establecido en el artículo 2 de las Disposiciones Constitucionales Transitorias el día 7 de septiembre de 1993 y con la ratificación del electorado, a través de plebiscito (Alcántara Sáez, 2013), la forma republicana y el sistema de gobierno presidencialista.

De acuerdo con Ernani Contipelli (2012) "no cabe duda que Brasil organiza territorialmente su poder como forma de Estado Federal” (p. 34). La organización políticoadministrativa adoptada de conformidad con la CRFB, según el mencionado autor, delinea cuatro niveles autónomos de gobierno: la Unión (representante del poder central), los Estados (Estados-miembros), el Distrito Federal y los Municipios (artículo 18 de la CRFB).

En su artículo 24, inciso VII, la CRFB, establece la competencia concurrente de la Unión, los Estados y el Distrito Federal para legislar sobre la protección del patrimonio turístico. Asimismo, contiene una disposición de gran trascendencia respecto del turismo en su artículo 180, que reza: "La Unión, los Estados, el Distrito Federal y los Municipios promoverán e incentivarán el turismo como factor de desarrollo social y económico. Este precepto es de gran importancia ya que: la elección política de la Asamblea Nacional Constituyente confirmó la vocación turística del país y planteó un deber estatal de atención hacia la actividad, ahora con status jurídico constitucional" (la traducción es propia) (De Lacerda Badaró, 2010, p. 19). De esta prescripción constitucional se extrae la existencia de competencias turísticas en todos los niveles del Estado, cuyo reparto puede resumirse en el cuadro que se acompaña.

Tabla № 2. Competencias en materia turística en la República Federativa del Brasil 


\begin{tabular}{|c|c|}
\hline \multirow[t]{10}{*}{ Unión } & $\begin{array}{l}\text { Buscar la integración económica, política, social y cultural de los pueblos de } \\
\text { América Latina, con vistas a la formación de una comunidad latinoamericana } \\
\text { de naciones (artículo 4, parágrafo único). }\end{array}$ \\
\hline & $\begin{array}{l}\text { Establecer el procedimiento para la expropiación por causa de necesidad o } \\
\text { utilidad pública (artículo 5, inciso XXIV, CRFB). }\end{array}$ \\
\hline & $\begin{array}{l}\text { Asegurar el derecho de los autores a la propiedad de marcas, de los nombres } \\
\text { de empresas y de otros signos distintivos, teniendo en cuenta el interés social } \\
\text { y el desarrollo económico del País (artículo } 5 \text {, inciso XXIX, CRFB). }\end{array}$ \\
\hline & Promover la defensa del consumidor (artículo 5, inciso XXXII, CRFB). \\
\hline & $\begin{array}{l}\text { Aprobar los tratados y convenciones internacionales sobre derechos humanos } \\
\text { que serán equivalentes a las enmiendas constitucionales siempre que se } \\
\text { aprueben en cada Cámara del Congreso Nacional por tres quintos de los votos } \\
\text { de los respectivos miembros (artículo 5, parágrafo 3, CRFB). }\end{array}$ \\
\hline & $\begin{array}{l}\text { Fijar el salario mínimo (artículo 7, inciso IV, CRFB), la protección del salario } \\
\text { (artículo 7, inciso X, CRFB), la participación en las ganancias de la empresa } \\
\text { (artículo 7, inciso XI, CRFB), la protección del mercado de trabajo de la mujer } \\
\text { (artículo 7, inciso XX, CRFB). }\end{array}$ \\
\hline & Crear, integrar, fusionar y desmembrar los Municipios (artículo 18 inciso IV). \\
\hline & $\begin{array}{l}\text { Fijar las normas para la cooperación entre la Unión, los Estados, el Distrito } \\
\text { Federal y los Municipios, con vistas al equilibrio del desarrollo y del bienestar } \\
\text { en el ámbito nacional (artículo 23, Párrafo Único). }\end{array}$ \\
\hline & $\begin{array}{l}\text { Mantener relaciones con los Estados extranjeros y participar en las } \\
\text { organizaciones internacionales (inciso I); Elaborar y ejecutar planes nacionales } \\
\text { y regionales de ordenación del territorio y de desarrollo económico y social } \\
\text { (inciso IX); Explotar directamente o mediante autorización, concesión o } \\
\text { licencia: la navegación aérea, aeroespacial y la infraestructura aeroportuaria, } \\
\text { los servicios de transporte ferroviario y acuático entre los puertos brasileños y } \\
\text { fronteras nacionales o que traspasen los límites de un Estado o Territorio, los } \\
\text { servicios de transporte por carretera interestatal e internacional de pasajeros, } \\
\text { los puertos marítimos, fluviales y lacustres (inciso XII, apartados } 3,4,5 \text { y 6); } \\
\text { Establecer directrices para el desarrollo urbano, incluyendo la vivienda, del } \\
\text { saneamiento básico y de los transportes urbanos (inciso XX); Establecer } \\
\text { principios y directrices para el sistema nacional de transportes (inciso XXI); } \\
\text { Ejecutar los servicios de policía marítima, aérea y de frontera (inciso XXII); } \\
\text { (artículo 21, CRFB). }\end{array}$ \\
\hline & $\begin{array}{l}\text { Legislar exclusivamente sobre: derecho civil, comercial, agrario, marítimo, } \\
\text { aeronáutico, espacial y del trabajo (inciso I); Expropiación (inciso II); Política de } \\
\text { cambio (inciso VII); Comercio exterior e interestatal (inciso VIII); Directrices de } \\
\text { la política nacional de transporte (inciso IX); Régimen de los puertos, } \\
\text { navegación lacustre, fluvial, marítima, aérea y aeroespacial (inciso XX); Tráfico }\end{array}$ \\
\hline
\end{tabular}




\begin{tabular}{|c|c|}
\hline & $\begin{array}{l}\text { y transporte (inciso XI); Poblaciones indígenas (inciso XIV); Emigración e } \\
\text { inmigración (inciso XV); Competencia de la policía federal y de las policías en } \\
\text { carretera y ferroviaria federales (inciso XXII); Directrices y bases de la } \\
\text { educación nacional (inciso 24), publicidad comercial (inciso XXVIII); Autorizar, } \\
\text { por una ley complementaria, a los Estados a legislar sobre cuestiones } \\
\text { específicas de las materias relacionadas en este artículo (parágrafo único) } \\
\text { (artículo 22, CRFB). }\end{array}$ \\
\hline & $\begin{array}{l}\text { Dictar la Ley que regula la organización de los territorios federales (artículo 33, } \\
\text { CRFB). }\end{array}$ \\
\hline & $\begin{array}{l}\text { Regular las condiciones para la integración de las regiones en desarrollo y los } \\
\text { incentivos regionales (artículo 43, CRFB). }\end{array}$ \\
\hline & $\begin{array}{l}\text { Fijar en el Territorio Federal, los impuestos estatales y si no estuviese dividido } \\
\text { en Municipios, los municipales (artículo 146, CRFB). }\end{array}$ \\
\hline & $\begin{array}{l}\text { Establecer impuestos sobre la importación de productos extranjeros y } \\
\text { exportación de productos nacionales o nacionalizados (artículo 153, CRFB) }\end{array}$ \\
\hline $\begin{array}{l}\text { Unión, } \\
\text { Estados, } \\
\text { Distrito } \\
\text { Federal }\end{array}$ & $\begin{array}{l}\text { Legislar concurrentemente en materia de: derecho tributario (inciso I); } \\
\text { Presupuesto (inciso II); Producción y consumo (inciso V); Florestas, caza, } \\
\text { pesca, fauna, conservación a la naturaleza, defensa del suelo y de los } \\
\text { recursos naturales, protección del medio ambiente y control de la polución } \\
\text { (inciso VI); Protección del patrimonio histórico, cultural, turístico y paisajístico } \\
\text { (inciso VII); Responsabilidad por daños al medio ambiente, al consumidor, a } \\
\text { los bienes y derechos de valor artístico, estético, histórico, turístico y } \\
\text { paisajístico (inciso VIII); educación, cultura, enseñanza y deporte (inciso IX); } \\
\text { Protección e integración social de las personas portadoras de deficiencias } \\
\text { (inciso XIV) (artículo 24, CRFB). }\end{array}$ \\
\hline $\begin{array}{l}\text { Unión, } \\
\text { Estados, } \\
\text { Distrito } \\
\text { Federal y } \\
\text { Municipios }\end{array}$ & $\begin{array}{l}\text { Proteger a las personas portadoras de deficiencias (inciso II); proteger los } \\
\text { documentos, las obras y otros bienes de valor histórico, artístico y cultural, los } \\
\text { monumentos, los paisajes naturales notables y los parajes arqueológicos } \\
\text { (inciso III); Proteger el medio ambiente (inciso VI); Preservar las florestas, la } \\
\text { fauna y la flora (inciso VII) (artículo 23, CRFB). }\end{array}$ \\
\hline & Establecer diferentes tributos (artículo 145, CRFB). \\
\hline & $\begin{array}{l}\text { Dispersar a las microempresas y a las empresas de pequeñas dimensiones, } \\
\text { tratamiento jurídico diferenciado, tendiendo a incentivarlas mediante la } \\
\text { simplificación de sus obligaciones administrativas, tributarias, de Seguridad } \\
\text { Social y crediticias, o la eliminación o reducción de éstas por medio de ley } \\
\text { (artículo 179, CRFB). }\end{array}$ \\
\hline $\begin{array}{l}\text { Congreso } \\
\text { Nacional }\end{array}$ & $\begin{array}{l}\text { Disponer sobre la organización administrativa y judicial de los territorios } \\
\text { (artículo 33, CRFB). }\end{array}$ \\
\hline & $\begin{array}{l}\text { Regular las condiciones para la integración de las Regiones, la composición de } \\
\text { los organismos e incentivos regionales (artículo 43, CRFB). }\end{array}$ \\
\hline
\end{tabular}




\begin{tabular}{|c|c|}
\hline & $\begin{array}{l}\text { Establecer el sistema tributario (inciso I); Aprobar planes y programas } \\
\text { nacionales, regionales y sectoriales de desarrollo (inciso IV); Determinar los } \\
\text { límites del territorio nacional, espacio aéreo y marítimo y bienes de la Unión; } \\
\text { Incorporar, subdividir o desmembrar áreas de los Territorios o Estados (inciso } \\
\text { VI); Creación, transformación y extinción de cargos, empleos y funciones } \\
\text { públicas (inciso 10); Creación y extinción de Ministerios y órganos de la } \\
\text { Administración Pública (inciso XI); Materia cambiaria (inciso XIII) (artículo 48, } \\
\text { CRFB). }\end{array}$ \\
\hline & $\begin{array}{l}\text { Resolver definitivamente sobre tratados, acuerdos o actos internacionales } \\
\text { (inciso I); Suspender los actos normativos del Poder Ejecutivo que excedan del } \\
\text { poder reglamentario o de los límites de la delegación legislativa (inciso V) } \\
\text { (artículo 49, CRFB). }\end{array}$ \\
\hline & $\begin{array}{l}\text { Regular la creación, estructuración y atribuciones de los Ministerios (artículo } \\
88, \text { CRFB). }\end{array}$ \\
\hline & $\begin{array}{l}\text { Establecer las directrices y las bases de planificación de un desarrollo nacional } \\
\text { equilibrado, que incorpore y compatibilice los planes nacionales y regionales } \\
\text { de desarrollo (artículo 174, parágrafo 1, CRFB). }\end{array}$ \\
\hline & Establecer el plan nacional de educación (artículo 214, CRFB). \\
\hline $\begin{array}{l}\text { Presidente } \\
\text { de la }\end{array}$ & $\begin{array}{l}\text { Adoptar medidas provisionales, con fuerza de ley, en caso de relevancia y } \\
\text { urgencia (artículo } 62, \mathrm{CRFB} \text { ). }\end{array}$ \\
\hline República & $\begin{array}{l}\text { Ejercer, con auxilio de los Ministros de Estado, la dirección superior de la } \\
\text { administración federal (inciso II); Sancionar, promulgar y hacer públicas la } \\
\text { leyes, así como dictar decretos y reglamentos para su fiel ejecución (inciso IV), } \\
\text { vetar proyectos de ley total o parcialmente (inciso V); Disponer, mediante } \\
\text { decreto, sobre: a) organización y funcionamiento de la administración federal, } \\
\text { cuando no implique aumento de gasto ni creación o extinción de órganos } \\
\text { públicos; b) extinción de funciones o cargos públicos, cuando se encuentren } \\
\text { vacantes (inciso VI); Celebrar tratados, convenciones y actos internacionales, } \\
\text { sujetos a refrendo del Congreso Nacional (inciso VIII); Proveer y extinguir los } \\
\text { cargos públicos federales (inciso XXV); Dictar medidas provisionales con } \\
\text { fuerza de ley en los términos establecidos en la Constitución (artículo 84, } \\
\text { CRFB). }\end{array}$ \\
\hline $\begin{array}{l}\text { Ministros de } \\
\text { Estado }\end{array}$ & $\begin{array}{l}\text { Disponer, en caso de delegación por parte del Presidente de la República: a) la } \\
\text { organización y funcionamiento de la administración federal, cuando no } \\
\text { implique aumento de gasto ni creación o extinción de órganos públicos; b) la } \\
\text { extinción de funciones o cargos públicos, cuando se encuentren vacantes } \\
\text { (artículo 84, parágrafo único, CRFB). }\end{array}$ \\
\hline & $\begin{array}{l}\text { Ejercer la orientación, coordinación y supervisión de los órganos y entidades } \\
\text { de la Administración Federal en el área de su competencia y refrendar los } \\
\text { actos y decretos firmados por el Presidente de la República (inciso I); Expedir }\end{array}$ \\
\hline
\end{tabular}




\begin{tabular}{|c|c|}
\hline & $\begin{array}{l}\text { instrucciones para la ejecución de leyes, decretos y reglamentos (inciso II) } \\
\text { (artículo } 87, \text { CRFB). }\end{array}$ \\
\hline \multirow[t]{2}{*}{$\begin{array}{l}\text { Estados } \\
\text { Federales }\end{array}$} & $\begin{array}{l}\text { Dictar sus propias Constituciones; Ejercer todas las competencias que no le } \\
\text { estén prohibidas por la Constitución (parágrafo 1); Instituir regiones } \\
\text { metropolitanas, aglomeraciones urbanas y micro regiones, constituidas por } \\
\text { agrupaciones de municipios limítrofes (parágrafo } 3 \text { ) (artículo 25, CRFB). }\end{array}$ \\
\hline & Establecer determinados impuestos (artículo 155, CRFB). \\
\hline \multirow[t]{3}{*}{ Municipios } & Dictar su Ley Orgánica (artículo 29, CRFB). \\
\hline & $\begin{array}{l}\text { Legislar sobre asuntos de interés local (inciso I); Suplementar la legislación } \\
\text { federal y estatal en lo que cupiese (inciso II); Establecer y recaudar los tributos } \\
\text { de su competencia (inciso III); Organizar y prestar los servicios públicos de } \\
\text { interés local, incluido el de transporte colectivo, (inciso V); Promover la } \\
\text { adecuada ordenación territorial, mediante la planificación y control del uso, de } \\
\text { la parcelación y de la ocupación del suelo urbano (inciso 8); Promover, la } \\
\text { protección del patrimonio histórico- cultural local (inciso 9) (artículo 30, CRFB). }\end{array}$ \\
\hline & $\begin{array}{l}\text { Ejecutar la política de desarrollo urbanístico, que tiene por objeto ordenar el } \\
\text { pleno desarrollo de las funciones sociales de la ciudad y garantizar el bienestar } \\
\text { de sus habitantes (artículo 182, CRFB). }\end{array}$ \\
\hline \multirow[t]{3}{*}{$\begin{array}{l}\text { Distrito } \\
\text { Federal }\end{array}$} & $\begin{array}{l}\text { Votar la Ley Orgánica que lo rige y ejercer las competencias legislativas } \\
\text { reservadas a los Estados y Municipios (artículo 32, CRFB). }\end{array}$ \\
\hline & Percibir los impuestos municipales (artículo 147, CRFB). \\
\hline & $v_{0}$ \\
\hline
\end{tabular}

Fuente: Elaboración propia

IV.3. Distribución de competencias en materia turística en la República del Paraguay

La Constitución vigente de la República del Paraguay (en adelante $\mathrm{CN}$ ), fue sancionada el 20 de junio de 1992, y a la fecha no cuenta con procesos de reforma. Adopta para su gobierno la democracia representativa, participativa y pluralista (artículo 1, $\mathrm{CN})$.

La CN adopta el Estado social de derecho, unitario, indivisible, y descentralizado en la forma que se establecen esta Constitución y las leyes (artículo 1 de la $\mathrm{CN}$ ) lo que implica según Camacho (2001, p. 799) "una ruptura con el pasado y una apuesta por una nueva forma de organización política y social." La CN distribuye territorialmente las competencias entre: el Estado, los Gobiernos Departamentales y los Gobiernos Municipales.

Dicha norma efectúa una mención a la actividad turística en su artículo 168, que incluye entre las atribuciones de las municipalidades, en su jurisdicción territorial y con arreglo a la ley, la libre gestión en materia de turismo. De acuerdo con el sistema de 
reparto adoptado pueden identificarse diferentes competencias, que se resumen en el cuadro siguiente.

Tabla № 3. Competencias en materia turística en la República del Paraguay

\begin{tabular}{|c|c|}
\hline \multirow[t]{7}{*}{ Estado } & $\begin{array}{l}\text { Organizar una política de integración de los discapacitados (artículo 58, } \\
\mathrm{CN} \text { ). }\end{array}$ \\
\hline & $\begin{array}{l}\text { Proveer gratuitamente de tierras a los pueblos indígenas, que tienen } \\
\text { derecho a la propiedad comunitaria de la tierra y estarán exentas de tributo } \\
\text { (artículo } 63, \mathrm{CN} \text { ). }\end{array}$ \\
\hline & Fomentar la enseñanza superior o universitaria (artículo 76, CN). \\
\hline & $\begin{array}{l}\text { Definir y registrar los objetos, documentos y espacios de valor histórico, } \\
\text { arqueológico, paleontológico, artístico o científico, que hacen parte del } \\
\text { patrimonio cultural de la Nación (artículo } 81, \mathrm{CN} \text { ). }\end{array}$ \\
\hline & $\begin{array}{l}\text { Desarrollar políticas que tiendan al pleno empleo y a la formación } \\
\text { profesional de recursos humanos (artículo } 87, \mathrm{CN} \text { ). }\end{array}$ \\
\hline & $\begin{array}{l}\text { Promover el desarrollo económico mediante la utilización racional de los } \\
\text { recursos disponibles, con el objeto de impulsar un crecimiento ordenado y } \\
\text { sostenido de la economía, de crear nuevas fuentes de trabajo y de riqueza, } \\
\text { de acrecentar el patrimonio nacional y de asegurar el bienestar de la } \\
\text { población (artículo 176, CN). }\end{array}$ \\
\hline & $\begin{array}{l}\text { Establecer impuestos, tasas, contribuciones y demás recursos (artículo 178, } \\
\mathrm{CN} \text { ). }\end{array}$ \\
\hline \multirow[t]{11}{*}{ Congreso } & $\begin{array}{l}\text { Legislar sobre la preservación, la conservación, la recomposición y el } \\
\text { mejoramiento del ambiente (artículo } 7, \mathrm{CN} \text { ). }\end{array}$ \\
\hline & $\begin{array}{l}\text { Regular las actividades susceptibles de producir alteración ambiental } \\
\text { (artículo 8, CN). }\end{array}$ \\
\hline & $\begin{array}{l}\text { Legislar la publicidad para la mejor protección de los derechos del } \\
\text { consumidor (artículo 27, CN). }\end{array}$ \\
\hline & Reglamentar las migraciones (artículo $41, \mathrm{CN}$ ). \\
\hline & Legislar la colegiación personal (artículo 42, CN). \\
\hline & Establecer tributos (artículo 44, CN). \\
\hline & Crear Universidades públicas o privadas (artículo 79, CN). \\
\hline & Proteger el trabajo en todas sus formas (artículo 86, CN). \\
\hline & Establecer la expropiación por causa de utilidad pública (artículo 109, CN). \\
\hline & $\begin{array}{l}\text { Arreglar el gozo del derecho de propiedad exclusiva por parte del autor, } \\
\text { inventor, productor de su obra, invención, marca o nombre comercial } \\
\text { (artículo } 110, \mathrm{CN} \text { ). }\end{array}$ \\
\hline & Aprobar tratados internacionales (artículo 141, CN). \\
\hline
\end{tabular}




\begin{tabular}{|c|c|}
\hline & $\begin{array}{l}\text { Denunciar tratados internacionales de derechos humanos, según el } \\
\text { procedimiento para la enmienda de la Constitución (artículo 142, CN). }\end{array}$ \\
\hline & $\begin{array}{l}\text { Admitir un orden jurídico supranacional en condiciones de igualdad con } \\
\text { otros Estados (artículo 145, CN). }\end{array}$ \\
\hline & $\begin{array}{l}\text { Crear, fusionar o modificar los departamentos y sus capitales, los } \\
\text { municipios y los distritos (artículo } 159, \mathrm{CN} \text { ). }\end{array}$ \\
\hline & Regular la constitución y funcionamiento de las regiones (artículo 160, CN). \\
\hline & Crear impuestos, tasas y contribuciones (artículo 164, CN). \\
\hline & $\begin{array}{l}\text { Determinar las diferentes categorías y regímenes de municipalidades } \\
\text { (artículo } 171, \mathrm{CN}) \text {. }\end{array}$ \\
\hline & $\begin{array}{l}\text { Dictar los códigos y demás leyes (inciso 2); Establecer la división política } \\
\text { del territorio de la República, su organización regional, departamental y } \\
\text { municipal (inciso 3); Legislar sobre materia tributaria, (inciso 4); Sancionar } \\
\text { el Presupuesto General de la Nación (inciso 5); Aprobar o rechazar los } \\
\text { tratados y acuerdos internacionales suscritos por el Poder ejecutivo (inciso } \\
\text { 9); Dictar leyes de organización de la administración de la República y crear } \\
\text { entes descentralizados (inciso 12); Reglamentar la navegación fluvial, } \\
\text { marítima, aérea y espacial (inciso 21) (artículo 202, CN). }\end{array}$ \\
\hline & $\begin{array}{l}\text { Determinar el número de Ministros del Poder Ejecutivo y sus funciones } \\
\text { (artículo } 240, \mathrm{CN} \text { ). }\end{array}$ \\
\hline $\begin{array}{l}\text { Presidente de la } \\
\text { República }\end{array}$ & $\begin{array}{l}\text { Dirigir la administración general del país (inciso 1); Participar en la } \\
\text { formación de las leyes, promulgarlas y hacerlas publicar, reglamentarlas y } \\
\text { controlar su cumplimiento (inciso 3); Vetar, total o parcialmente, las leyes } \\
\text { sancionadas por el Congreso (inciso 4); Dictar decretos (inciso 5); Nombrar } \\
\text { y remover a los Ministros y funcionarios de la Administración Pública (inciso } \\
\text { 6); Manejar las relaciones exteriores de la República, negociar y firmar } \\
\text { tratados internacionales (inciso 7) (artículo 238, CN). }\end{array}$ \\
\hline Ministros & $\begin{array}{l}\text { Administrar sus respectivas carteras promoviendo y ejecutando la política } \\
\text { relativa a las materias de su competencia (artículo } 243, \mathrm{CN} \text { ). }\end{array}$ \\
\hline $\begin{array}{l}\text { Gobierno } \\
\text { Departamental }\end{array}$ & $\begin{array}{l}\text { Organizar los servicios departamentales comunes, como obras públicas, } \\
\text { provisión de energía y de agua potable y los demás que afecten } \\
\text { conjuntamente a más de un Municipio (artículo } 163, \mathrm{CN} \text { ). }\end{array}$ \\
\hline $\begin{array}{l}\text { Gobierno } \\
\text { Municipal }\end{array}$ & $\begin{array}{l}\text { Gestionar en materia de urbanismo, ambiente, educación, cultura, deporte, } \\
\text { turismo, asistencia sanitaria, cuerpos de inspección y de policía (inciso 1), } \\
\text { elaborar su presupuesto (inciso 2), regular el monto de las tasas retributivas } \\
\text { de servicios (inciso 5), dictar ordenanzas, reglamentos y resoluciones } \\
\text { (inciso 6), reglamentar el transporte público (inciso 8) (artículo 168, CN). }\end{array}$ \\
\hline & $\begin{array}{l}\text { Recaudar los tributos que graven la propiedad inmueble en forma directa } \\
\text { (artículo } 169, \mathrm{CN} \text { ). }\end{array}$ \\
\hline
\end{tabular}


\begin{tabular}{|l|l} 
& Encarar \\
\hline Fuente: Elaboración propia
\end{tabular}

IV.4. Distribución de competencias en materia turística en la República Oriental del Uruguay

La Constitución vigente en la República Oriental del Uruguay (en adelante CR), fue plebiscitada el 27 de noviembre de 1966 y ha sufrido diversas reformas, aprobadas mediante ratificaciones plebiscitarias en los años 1989, 1994, 1996 y 2004. La CR adopta la forma democrática republicana (artículo 82, CR).

El modelo de Estado adoptado por la CR, de acuerdo con Gros Espiell y Gallicchio (2005) "es unitario y existen como manifestaciones de descentralización territorial las personas jurídicas gobiernos departamentales, que tienen como órganos necesarios una intendencia y una junta departamental..." (p. 164).

La CR contiene preceptos que refieren expresamente al turismo (Ferreyra, 2017), en primer lugar en el artículo 85, inciso 9, cuando entre las potestades de la Asamblea Nacional enuncia la de declarar de interés nacional zonas turísticas. Asimismo, en su artículo 288, en el que establece que una ley determinará las condiciones para la creación de las Juntas Locales y sus atribuciones pudiendo, bajo mayorías especiales y a solicitud del Gobierno Departamental, ampliar las facultades de gestión de aquellas, en las poblaciones que, entre otros aspectos, ofrezcan interés nacional para el desarrollo del turismo. Entre las disposiciones transitorias y especiales: Crea el Ministerio de Transporte, Comunicaciones y Turismo -actualmente Ministerio de Turismo- y determina que la Comisión Nacional de Turismo pasará a depender, en calidad de servicios centralizados, del Ministerio antes creado. No obstante esto, el Poder Ejecutivo podrá delegarle, bajo su responsabilidad y por decreto fundado, las competencias que estime necesarias para asegurar la eficacia y continuidad del cumplimiento de los servicios (Disposición E). Asimismo integra en la Comisión de Planeamiento y Presupuesto al Ministerio antes enunciado (Disposición O).

Tales menciones permiten advertir la importancia que el constituyente ha otorgado a la actividad, a la vez que establecen competencias con relación a la materia que se enuncian en adelante.

Tabla № 4. Competencias en materia turística en la República Oriental del Uruguay

\begin{tabular}{|l|l|}
\hline $\begin{array}{l}\text { Asamblea } \\
\text { General }\end{array}$ & $\begin{array}{l}\text { Procurar la integración social y económica de los Estados Latinoamericanos, } \\
\text { especialmente en lo que se refiere a la defensa común de sus productos y } \\
\text { materias primas (artículo 6, CR). }\end{array}$ \\
\cline { 2 - 2 } & Establecer leyes relativas al goce de los derechos al trabajo y la propiedad \\
\hline
\end{tabular}




\begin{tabular}{|c|c|}
\hline & Q). \\
\hline & $\begin{array}{l}\text { Determinar lo oportuno para la salvaguarda de la riqueza artística o histórica } \\
\text { del país (artículo } 34, \mathrm{CR} \text { ). }\end{array}$ \\
\hline & $\begin{array}{l}\text { Establecer limitaciones al trabajo, industria, comercio, profesión o cualquier } \\
\text { otra actividad lícita, por razones de interés general (artículo 36, CR). }\end{array}$ \\
\hline & Reglamentar la inmigración (artículo 37, CR). \\
\hline & Disponer la protección del medio ambiente (artículo 47, CR). \\
\hline & Promover las inversiones orientadas al comercio exterior (artículo 50, CR). \\
\hline & Proteger el derecho del autor, del inventor o del artista (artículo 33). \\
\hline & $\begin{array}{l}\text { Formar y mandar, publicar los Códigos (inciso 1); Fomentar la industria y el } \\
\text { comercio interior y exterior (inciso 3); Establecer contribuciones (inciso 4); } \\
\text { Aprobar los tratados de paz, alianza, comercio que celebre el Poder Ejecutivo } \\
\text { con potencias extranjeras (inciso 7); Crear Departamentos y fijar sus límites, } \\
\text { habilitar puertos, establecer aduanas y derechos de exportación e importación, } \\
\text { declarar de interés nacional zonas turísticas (inciso 9); Fijar el tipo de cambio } \\
\text { de la moneda (inciso 10); Crear o suprimir empleos públicos (inciso 13) } \\
\text { (artículo 85, CR). }\end{array}$ \\
\hline & $\begin{array}{l}\text { Dictar la Ley de Ministerios, su número, denominación, atribuciones y } \\
\text { competencias (artículo 174, CR). }\end{array}$ \\
\hline & Establecer la materia Departamental y municipal (artículo 262, CR). \\
\hline & $\begin{array}{l}\text { Determinar las condiciones para la creación de las Juntas Locales y sus } \\
\text { atribuciones (artículo } 288, \mathrm{CR} \text { ). }\end{array}$ \\
\hline & $\begin{array}{l}\text { Exonerar temporariamente de tributos nacionales y rebajar sus alícuotas } \\
\text { (artículo 298, CR). }\end{array}$ \\
\hline $\begin{array}{l}\text { Presidente de } \\
\text { la República }\end{array}$ & $\begin{array}{l}\text { Publicar las leyes, ejecutarlas, hacerlas ejecutar, expidiendo los reglamentos } \\
\text { especiales que sean necesarios (inciso 4); Objetar u observar los proyectos de } \\
\text { ley (inciso 6); Proponer a las Cámaras proyectos de ley (inciso 7); Proveer los } \\
\text { empleos civiles (inciso 9); Recaudar las rentas y darles el destino (inciso 18); } \\
\text { Concluir y suscribir tratados, necesitando para ratificarlos la aprobación del } \\
\text { Poder Legislativo (inciso 20); Conceder privilegios industriales conforme a las } \\
\text { leyes (inciso 21); Delegar las atribuciones que estime convenientes (inciso 24) } \\
\text { (artículo 168, CR). }\end{array}$ \\
\hline & Proyectar el Presupuesto (artículo 214, CR). \\
\hline $\begin{array}{l}\text { Ministros de } \\
\text { Estado }\end{array}$ & $\begin{array}{l}\text { Ejercer las atribuciones en sus respectivas carteras y de acuerdo con las leyes } \\
\text { y las disposiciones del Poder Ejecutivo (artículo 181, CR). }\end{array}$ \\
\hline Junta & Aprobar el proyecto de presupuesto de los Intendentes (artículo 224, CR). \\
\hline Departamental & $\begin{array}{l}\text { Ejercer el Gobierno y la Administración de los Departamentos (artículo 262, } \\
\text { CR). }\end{array}$ \\
\hline & Organizar y prestar servicios y actividades propias en sus territorios como en \\
\hline
\end{tabular}




\begin{tabular}{|l|l|}
\hline \multirow{5}{*}{$\begin{array}{l}\text { Municipal } \\
\text { Intendente }\end{array}$} & $\begin{array}{l}\text { forma regional o interdepartamental (artículo 262, CR). } \\
\text { Sancionar los presupuestos (inciso 2); Crear impuestos, tasas, contribuciones, } \\
\text { tarifas y precios de los servicios que presten (inciso 3); Otorgar concesiones } \\
\text { para servicios públicos (inciso 8); Solicitar del Poder Legislativo modificaciones } \\
\text { o ampliaciones de la Ley Orgánica de los Gobiernos Departamentales (inciso } \\
\text { 11) (artículo 273, CR). }\end{array}$ \\
\hline $\begin{array}{l}\text { Ejercer el Gobierno y la Administración de los Departamentos (artículo 262, } \\
\text { CR) }\end{array}$ & $\begin{array}{l}\text { Promulgar y publicar los decretos sancionados por la Junta Departamental } \\
\text { (inciso 2); Preparar el presupuesto (inciso 3); Proponer a la Junta } \\
\text { Departamental, impuestos, tasas y contribuciones (inciso 4); Nombrar los } \\
\text { empleados (inciso 5); Designar bienes a expropiarse (inciso 7) (artículo 275, } \\
\text { CR). }\end{array}$ \\
\cline { 2 - 3 } & $\begin{array}{l}\text { Determinar la competencia de las direcciones generales de departamento y } \\
\text { modificar su denominación (artículo 279, CR). }\end{array}$ \\
\hline
\end{tabular}

Fuente: Elaboración propia

IV.5. Distribución de Competencias en materia turística en la República Bolivariana de Venezuela

La Constitución de la República Bolivariana de Venezuela (en adelante CRBV), sancionada y aprobada mediante referéndum el 15 de diciembre de 1999 se reformó en el año 2009. Fue redactada con el objetivo de transformar el Estado y su ordenamiento jurídico, con el fin de avanzar hacia una democracia social y participativa (Viciano Pastor y Salamanca, 2006), bajo la forma republicana (artículo 1 CRBV) y de Estado democrático y social de Derecho y Justicia (artículo 2 CRBV).

La CRBV adopta como forma de Estado el modelo federal descentralizado (artículo 4, CRBV). En su artículo 16 la CRVB señala "Con el fin de organizar políticamente la República, el territorio nacional se divide en el de los Estados, el del Distrito Capital, el de las dependencias federales y el de los territorios federales. El territorio se organiza en Municipios".

Dicha norma contiene disposiciones relativas al turismo, entre la que destacan la del artículo 156 que establece entre las competencias del Poder Público Nacional las políticas nacionales y la legislación en materia de turismo (inciso 23, CRBV). Por otra parte en su artículo 168 identifica, entre las competencias de los municipios, el área de turismo local (inciso 1). No obstante el reconocimiento más importante a la actividad se lo puede identificar en la cláusula contenida en el artículo 310 de la CRVB, que señala: "El turismo es una actividad económica de interés nacional, prioritaria para el país en su estrategia de 
diversificación y desarrollo sustentable. Dentro de las fundamentaciones del régimen socioeconómico previsto en esta Constitución, el Estado dictará las medidas que garanticen su desarrollo. El Estado velará por la creación y fortalecimiento del sector turístico nacional."

Es clara la trascendencia de las disposiciones citadas, ya que, como recuerda Urdaneta Salinas (2002, p. 11) es en la Constitución Nacional en la que se encuentran los fundamentos legales de las actividades dirigidas al desarrollo del turismo, y además de determinar la importancia que reviste la actividad, permiten configurar el sistema de distribución de competencias que se detallan en adelante.

Tabla № 5. Competencias en materia turística en la República Bolivariana de Venezuela

\begin{tabular}{|c|c|}
\hline \multirow{10}{*}{$\begin{array}{l}\text { Poder Público } \\
\text { Nacional }\end{array}$} & Promover la prosperidad y bienestar del pueblo (artículo 3, CRBV). \\
\hline & $\begin{array}{l}\text { Reconocer y proteger la propiedad intelectual sobre las obras científicas, } \\
\text { literarias y artísticas, invenciones, innovaciones, denominaciones, patentes, } \\
\text { marcas y lemas (artículo 98, CRBV). }\end{array}$ \\
\hline & $\begin{array}{l}\text { Garantizar la protección y preservación, enriquecimiento, conservación y } \\
\text { restauración del patrimonio cultural, tangible e intangible, y la memoria } \\
\text { histórica de la Nación (artículo 99, CRBV). }\end{array}$ \\
\hline & Reconocer la autonomía universitaria (artículo 109, CRBV). \\
\hline & $\begin{array}{l}\text { Promoción de la iniciativa privada, la libertad de trabajo, empresa, comercio, } \\
\text { industria, sin perjuicio de su facultad para dictar medidas para planificar, } \\
\text { racionalizar y regular la economía e impulsar el desarrollo integral del país } \\
\text { (artículo } 112, \mathrm{CRBV} \text { ). }\end{array}$ \\
\hline & $\begin{array}{l}\text { Adoptar las medidas necesarias destinadas a la protección del público } \\
\text { consumidor (artículo 113, CRBV). }\end{array}$ \\
\hline & $\begin{array}{l}\text { Reconocer la existencia de los pueblos y comunidades indígenas, su } \\
\text { organización social, política y económica, sus culturas, usos y costumbres, } \\
\text { idiomas y religiones, así como su hábitat y derechos originarios sobre las } \\
\text { tierras que ancestral y tradicionalmente ocupan y que son necesarias para } \\
\text { desarrollar y garantizar sus formas de vida (artículo 119, CRBV). }\end{array}$ \\
\hline & $\begin{array}{l}\text { Proteger el ambiente, la diversidad biológica, los procesos ecológicos, los } \\
\text { parques nacionales y monumentos naturales y demás áreas de especial } \\
\text { importancia ecológica (artículo 127, CRBV). }\end{array}$ \\
\hline & $\begin{array}{l}\text { Atribuir a organizaciones supranacionales, mediante tratados, el ejercicio de } \\
\text { las competencias necesarias para llevar a cabo estos procesos de } \\
\text { integración (artículo 153, CRBV). }\end{array}$ \\
\hline & $\begin{array}{l}\text { Organizar el régimen del Distrito Capital y de las dependencias federales } \\
\text { (inciso 10); regular el régimen cambiario (inciso 11); crear, organizar, } \\
\text { recaudar, administrar y controlar los impuestos y gravámenes a la }\end{array}$ \\
\hline
\end{tabular}




\begin{tabular}{|c|c|}
\hline & $\begin{array}{l}\text { importación y exportación de bienes y servicios (inciso 12); garantizar la } \\
\text { coordinación y armonización de las distintas potestades tributarias (inciso } \\
\text { 13); establecer el régimen de aduanas (inciso 15); legislar sobre ordenación } \\
\text { urbanística (inciso 19); legislar en materia de ambiente, aguas, turismo y } \\
\text { ordenación del territorio (inciso 23); fijar el régimen de la navegación y del } \\
\text { transporte aéreo, terrestre, marítimo, fluvial y lacustre, de carácter nacional; } \\
\text { de los puertos, aeropuertos y su infraestructura (inciso 26); establecer el } \\
\text { sistema de vialidad y de ferrocarriles nacionales (inciso 27), dictar la } \\
\text { legislación en materia civil, mercantil, de expropiación por causa de utilidad } \\
\text { pública o social; de propiedad intelectual, artística e industrial; del patrimonio } \\
\text { cultural y arqueológico, de inmigración, de pueblos indígenas y territorios } \\
\text { ocupados por ellos; del trabajo, de organización y funcionamiento de los } \\
\text { órganos del Poder Público Nacional y demás órganos e instituciones } \\
\text { nacionales del Estado (inciso 32) (artículo 156, CRBV). }\end{array}$ \\
\hline & $\begin{array}{l}\text { Promover el desarrollo armónico de la economía nacional (artículo 298, } \\
\text { CRBV). }\end{array}$ \\
\hline $\begin{array}{l}\text { Asamblea } \\
\text { Nacional }\end{array}$ & $\begin{array}{l}\text { Dictar una ley orgánica que garantice la autonomía municipal y la } \\
\text { descentralización político administrativa y dar a un territorio federal, por ley } \\
\text { especial, la categoría de Estado, asignándosele la totalidad o una parte de la } \\
\text { superficie del territorio respectivo (artículo 16, CRBV). }\end{array}$ \\
\hline & $\begin{array}{l}\text { Señalar el régimen y administración de las dependencias federales (artículo } \\
17, \mathrm{CRBV} \text { ). }\end{array}$ \\
\hline & $\begin{array}{l}\text { Garantizar las condiciones jurídicas y administrativas para que la igualdad } \\
\text { ante la ley sea real y efectiva; adoptando medidas positivas a favor de } \\
\text { personas o grupos que puedan ser discriminados, marginados o vulnerables } \\
\text { (artículo 21, inciso 2, CRBV). }\end{array}$ \\
\hline & $\begin{array}{l}\text { Establecer limitaciones al ejercicio del libre tránsito de personas en el } \\
\text { territorio (artículo 50, CRBV). }\end{array}$ \\
\hline & Reglamentar el derecho de asociación con fines lícitos (artículo 52, CRBV). \\
\hline & $\begin{array}{l}\text { Garantizar el respeto a la dignidad humana, de toda persona con } \\
\text { discapacidad o necesidades especiales y el derecho al ejercicio pleno y } \\
\text { autónomo de sus capacidades y a su integración familiar y comunitaria } \\
\text { (artículo 81, CRBV). }\end{array}$ \\
\hline & Establecer restricciones a la libertad de trabajo (artículo 87, CRBV). \\
\hline & $\begin{array}{l}\text { Establecer la forma y el procedimiento para la determinación del salario } \\
\text { mínimo vital (artículo 91, CRBV). }\end{array}$ \\
\hline & $\begin{array}{l}\text { Determinar las profesiones que requieren título y las condiciones que deben } \\
\text { cumplirse para ejercerlas, incluyendo la colegiación (artículo 105, CRBV). }\end{array}$ \\
\hline & $\begin{array}{l}\text { Determinar, por razones de desarrollo humano, seguridad, sanidad, } \\
\text { protección del ambiente u otras de interés social, limitaciones al libre }\end{array}$ \\
\hline
\end{tabular}




\begin{tabular}{|c|c|}
\hline & de la activ \\
\hline & $\begin{array}{l}\text { Someter a la propiedad a contribuciones, restricciones y obligaciones } \\
\text { (artículo } 115, \mathrm{CRBV} \text { ). }\end{array}$ \\
\hline & $\begin{array}{l}\text { Establecer los procedimientos de defensa del público consumidor (artículo } \\
117, \mathrm{CRBV} \text { ). }\end{array}$ \\
\hline & Establecer impuestos, tasas y contribuciones (artículo 133, CRBV). \\
\hline & Aprobar los tratados celebrados por la República (artículo 154, CRBV). \\
\hline & $\begin{array}{l}\text { Atribuir a los Municipios o a los Estados determinadas materias de la } \\
\text { competencia nacional, a fin de promover la descentralización (artículo 158, } \\
\text { CRBV). }\end{array}$ \\
\hline & $\begin{array}{l}\text { Regular el régimen de la organización y el funcionamiento del Consejo } \\
\text { Legislativo (artículo 16, CRBV). }\end{array}$ \\
\hline & $\begin{array}{l}\text { Dictar leyes de bases en materias objeto de competencias concurrentes } \\
\text { (artículo 165, CRBV). }\end{array}$ \\
\hline & $\begin{array}{l}\text { Discutir y aprobar el presupuesto nacional (inciso 6), aprobar los tratados o } \\
\text { convenios internacionales que celebre el Ejecutivo Nacional (inciso 18) } \\
\text { (artículo 187, CRBV). }\end{array}$ \\
\hline & $\begin{array}{l}\text { Dictar leyes habilitantes fin de establecer las directrices, propósitos y marco } \\
\text { de las materias que se delegan al Presidente o Presidenta de la República, } \\
\text { con rango y valor de ley (artículo 203, CRBV). }\end{array}$ \\
\hline & $\begin{array}{l}\text { Aprobar una ley especial sobre el régimen del Distrito Capital (Disposición } \\
\text { Transitoria Primera). }\end{array}$ \\
\hline Presidente 0 & Promulgar las leyes (artículo 214, CRBV). \\
\hline $\begin{array}{l}\text { Presidenta de } \\
\text { la República }\end{array}$ & $\begin{array}{l}\text { Dirigir las relaciones exteriores de la República y celebrar y ratificar los } \\
\text { tratados, convenios o acuerdos internacionales (inciso 4); Dictar, previa } \\
\text { autorización por una ley habilitante, decretos con fuerza de ley (inciso 8); } \\
\text { Reglamentar total o parcialmente las leyes, sin alterar su espíritu, propósito y } \\
\text { razón (inciso 10); Nombrar y remover a funcionarios (inciso 16); Fijar el } \\
\text { número, organización y competencia de los ministerios y otros organismos } \\
\text { de la Administración Pública Nacional (inciso 20) (artículo 236, CRBV). }\end{array}$ \\
\hline & Nombrar Ministros (artículo 243, CRBV). \\
\hline $\begin{array}{l}\text { Ministros } 0 \\
\text { Ministras }\end{array}$ & $\begin{array}{l}\text { Participar en el Consejo de Ministros y asesorar al Presidente o Presidenta } \\
\text { de la República y al Vicepresidente Ejecutivo o Vicepresidenta Ejecutiva en } \\
\text { los asuntos que les fueren asignados (artículo } 243^{\circ} \text {, CRBV). }\end{array}$ \\
\hline $\begin{array}{l}\text { Poder Público } \\
\text { Estadal }\end{array}$ & $\begin{array}{l}\text { Dictar su Constitución para organizar los poderes públicos (inciso 1); } \\
\text { Organizar sus Municipios y demás entidades locales (inciso 2); organizar, } \\
\text { recaudar, controlar y administrar los ramos tributarios propios; conservación, } \\
\text { administración y aprovechamiento de carreteras y autopistas nacionales, así } \\
\text { como de puertos y aeropuertos de uso comercial (inciso 10) (artículo 164, } \\
\text { CRBV). }\end{array}$ \\
\hline
\end{tabular}




\begin{tabular}{|l|l|}
\hline \multirow{2}{*}{$\begin{array}{l}\text { Legislativo } \\
\text { Gojo }\end{array}$} & $\begin{array}{l}\text { Legislar sobre las materias de la competencia estadal, Sancionar la Ley de } \\
\text { Presupuesto del Estado (artículo 162, CRBV). }\end{array}$ \\
\cline { 2 - 3 } $\begin{array}{l}\text { Mictar leyes de desarrollo en materias objeto de competencias concurrentes } \\
\text { (artículo 165, CRBV). }\end{array}$ \\
\hline Poder Público & $\begin{array}{l}\text { Ejercer el gobierno y la administración de cada Estado. } \\
\text { ambiente, abasto, educación, cultura, deporte, turismo, asistencia sanitaria y } \\
\text { social, instituciones de crédito, cuerpos de inspección y de policía (inciso 1); } \\
\text { crear, recaudar e invertir sus ingresos (inciso 3) (artículo 168, CRBV). }\end{array}$ \\
\cline { 2 - 3 } & $\begin{array}{l}\text { Ordenar el territorio y el espacio urbano; patrimonio histórico; turismo local; } \\
\text { parques y jardines, plazas, balnearios y otros sitios de recreación (inciso 1); } \\
\text { Vialidad urbana; circulación y ordenación del tránsito de vehículos y } \\
\text { personas en las vías municipales; servicios de transporte público urbano } \\
\text { (inciso 2); } \\
\text { Protección del ambiente, aseo urbano, recolección y tratamiento de residuos } \\
\text { (inciso 4); Servicio de agua potable, alcantarillado, canalización y disposición } \\
\text { de aguas servidas (inciso 6); Policía municipal (inciso 7) (artículo 178, } \\
\text { CRBV). }\end{array}$ \\
\hline $\begin{array}{l}\text { Distrito Capital } \\
3\end{array}$ & \begin{tabular}{l} 
Ejercer las competencias determinadas en una Ley Especial. \\
\hline
\end{tabular} \\
\hline
\end{tabular}

Fuente: Elaboración propia

\section{Conclusiones}

Los instrumentos constitucionales analizados, correspondientes a los países de América Latina, que son Estados Partes del Mercosur, responden a modelos de Estado y sistemas de distribución territorial diferentes. Si bien todos los países han adoptado la forma de gobierno republicana, en cuanto a la forma de Estado, Argentina, Brasil y Venezuela han adoptado el modelo federal, en tanto que Uruguay y Paraguay el modelo unitario. Ello constituye el primer escollo al intentar estudiarlos en conjunto, a fin de determinar en cada caso cómo se efectúa la distribución de competencias en materia turística en ellos.

El sistema de reparto en los países que adoptaron el modelo de Estado federal presenta mayor complejidad que en aquellos que han adoptado por el centralizado. No obstante puede advertirse que, con carácter general, todos los niveles de descentralización territorial, independientemente del modelo adoptado, cuentan con competencias propias en turismo, al menos con incidencia en la materia. 
La diferencia en la distribución de competencias entre los modelos centralizado y federal es sustantiva en cuanto a las potestades legislativas en materia turística, ya que en el primero de ellos se encuentran concentradas en el órgano que ejerce el Poder Legislativo Nacional, y en algunos casos en el Poder Ejecutivo Nacional, en tanto que en el caso de los Estados federales se reparten entre los entes que lo integran: Estado Nacional (Gobierno Nacional, Unión o Poder Público Nacional) y los Estados (Provincias, Estados Federales, Poder Público Estadal).

En ambos modelos lo que se advierte es la existencia de competencias con incidencia en el turismo en los municipios, con un grado de desarrollo diverso en las normas constitucionales analizadas, a excepción de la Constitución de la República Oriental del Uruguay, que delega la delimitación de los cometidos respectivos de las autoridades locales a una ley de la Asamblea General.

La competencia para aprobar tratados internacionales, de gran trascendencia en materia turística, constituye una potestad de carácter nacional y compleja en la que intervienen el Poder Ejecutivo Nacional (que se encarga de la suscripción y ratificación) y el Poder Legislativo Nacional (encargado de la aprobación), sin perjuicio de la facultad de revisión del Poder Judicial. La Constitución Nacional en la República Argentina, por su parte, admite la competencia de las provincias para "celebrar convenios internacionales en tanto no sean incompatibles con la política exterior de la Nación y no afecten las facultades delegadas al Gobierno federal o el crédito público de la Nación (artículo 124 CN)."

La República Argentina, la República del Paraguay y la República Bolivariana de Venezuela admiten un orden jurídico supranacional y la facultad de atribuir competencias en organizaciones de esta naturaleza en sus constituciones, ${ }^{4}$ a diferencia de los restantes países integrantes del bloque regional que no la reconocen de forma expresa. Esta circunstancia puede constituirse en un obstáculo a la hora de favorecer la creación de entes dentro del Mercosur en los que se deleguen competencias, particularmente, la de regulación de la actividad turística. No obstante para autores como Perotti (2011), refiriéndose a la integración regional en el caso de Brasil, esta circunstancia no restringe las posibilidades de creación y profundización del proceso dejando abierta la alternativa de un esquema meramente intergubernamental o de conformación supranacional.

En el caso de los países que adoptaron el modelo federal existe un precepto de similares características, a modo de cláusula de comercio, que reserva para el Estado nacional la regulación de las actividades comerciales (entre ellas las turísticas) que revisten el carácter de interestatal o internacional. Por otro lado se advierte una cláusula de cierre del sistema de distribución de competencias que reserva para los Estados las competencias no delegadas en el Estado federal (artículo 121, CN) o que no les estén prohibidas (artículo 25, parágrafo 1, CRFB) o que no correspondan a la competencia nacional o municipal (artículo 164, inciso 11, CRBV), lo que indica que las competencias 
turísticas que emanan de la aplicación de estos preceptos son reservadas con carácter general a las Provincias, los Estados Federales o al Poder Público Estadal, según corresponda.

Todos los países han otorgado carácter constitucional a los derechos de los consumidores, a excepción de la República Oriental del Uruguay, lo que es de gran significancia en materia turística, en la medida en que no puede dejar de reconocerse la condición de consumidor del turista, lo que lo convierte centro de todo el sistema protectorio con fundamento en la propia Constitución.

En las competencias que tienen impacto en la actividad turística, en las que se advierte un carácter concurrente entre el Estado Nacional y los Estados que integran la Federación se observa una suerte de prelación del ordenamiento jurídico nacional respecto del estadual, en el cual corresponde al primero el dictado de las normas generales y a los restantes su complemento, sin contrariar a las dictadas por aquel.

Se concluye en la importancia de afianzar los procesos de integración turística, entre los países de América Latina, en especial los que integran el MERCOSUR, con la finalidad de cooperar en su desarrollo de manera sostenible. Para ello se propicia la armonización de la normativa en la materia, a fin de evitar, en la medida de lo posible, ordenamientos jurídicos asimétricos, empleando para ello instrumentos de cooperación como la Reunión Especializada de Turismo de los Estados Partes del Mercosur y respetando las potestades que emanan de los diferentes sistemas de distribución de competencias en materia turística.

\section{Notas}

1 Esto se dispone en el Artículo 13 del Protocolo de Adhesión del Estado Plurinacional de Bolivia al MERCOSUR.

${ }^{2}$ La Ciudad de Buenos Aires posee un régimen de autonomía, conforme lo establecido en el artículo 127 de la CN, cuyo estatus es diferente del de los municipios.

${ }^{3}$ El artículo 18 de la CRBV crea un sistema de gobierno municipal a dos niveles, los Municipios del nuevo Distrito Capital (que sustituye al Distrito Federal) y los correspondientes al Estado de Miranda, y remitiendo a la ley su organización, gobierno, administración, competencia y recursos (Combellas, 2001, p. 54).

${ }^{4}$ Brewer-Carías, A. R. (2001) en Reflexiones sobre el constitucionalismo en América sostiene que este hecho "ha dado solución constitucional a un problema que, de otra forma, sería insoluble, que es la limitación de la soberanía de los Estados en beneficio de un poder supranacional, sin que esté expresamente previsto y autorizado en la Constitución" (p. 15).

\section{Referencias bibliográficas}

Alcantara Sáez, M. (2013). Sistemas políticos de América Latina, 4ta Edición. Madrid: Editorial Tecnos. 
Álvarez Conde, E. (2008). Curso de Derecho Constitucional, 6º Edición. Madrid: Editorial Tecnos.

Bidart Campos, G. J. (2005). Manual de la Constitución Reformada. III Tomos. Buenos Aires: Ediar Sociedad Anónima Editora, Comercial, Industrial y Financiera.

Blasco, A. (1981). Sobre el concepto de competencias exclusivas. Civitas, Revista Española de Derecho Administrativo 29, 307-318.

Brewer-Carías, A. R. (2001). Reflexiones sobre el constitucionalismo en América. Caracas: Editorial Jurídica Venezolana.

Camacho, E. (2000). La Constitución paraguaya de 1992. En Morodo, R. y De Vega, P. (Directores). Estudios de Teoría del estado y Derecho Constitucional en honor a Pablo Lucas Verdú (pp. 779-812). México: Universidad Autónoma de México.

Combellas, R. (2001). Derecho constitucional. Una introducción al estudio de la Constitución de la República Bolivariana de Venezuela. Caracas: Mc Graw-Hill Interamericana de Venezuela S.A.

Comas, M. S. (2012). A 20 años de la creación del Mercosur. Un largo camino hacia la integración. Revista del Colegio de Abogados de La Plata. Doctrina, Legislación, Jurisprudencia, LIV (75), 93-101.

Contipelli, E. (2012). Federación y Estado Autonómico: Estudio de Derecho constitucional comparado Brasil-España. Granada: Editorial Comares SL.

de Lacerda Badaró, R. A. (2010). Turismo, constituição e a lei do turismo. Considerações sobre o ordenamento jurídico brasileiro para um Direito do Turismo. En Benítez, D. (Coordinador). Derecho del turismo iberoamericano (pp. 17-32). Editorial LibrosEnRed.

del Busto, E. (2009). Marco regulatorio de la actividad de alojamiento turístico en la República Argentina. En Güidi, G. (Comp.). Conferencias y Ponencias del Primer Congreso Iberoamericano de Derecho del Turismo (pp. 363-372). Buenos Aires: Ladevi Ediciones. 
del Busto, E. (2014). El rol del derecho en el desarrollo del turismo. En Wallingre, N. y Villar, A. (Comp.). Gestión de municipios turísticos. Instrumentos básicos de acción (pp. 57-90). Bernal: Universidad Nacional de Quilmes.

Esain, J. (2004). El federalismo ambiental. Reparto de competencias legislativas en materia ambiental en la Constitución Nacional y la Ley General del Ambiente 25.675. En Jurisprudencia Argentina, Tomo 2004 I, 776-802.

Ferreira, H. (2017). La legislación turística en Uruguay. En International Journal of Scientific Management and Tourism; 3(3), 181-206.

González del Miño, P. (2012). Globalización, relaciones internacionales y turismo. En de Esteban Alonso, A. (Director). Turismo y relaciones internacionales. Aspectos sociales, culturales, económicos y ambientales (pp. 39-68). Madrid: DYKINSON S.L.

Gordillo, A. (2012). Tratado de derecho administrativo y obras selectas. Buenos Aires: Fundación de Derecho Administrativo.

Gros Espiell, H. y Esteva Gallicchio, E. G. (2005). Constituciones Iberoamericanas. Uruguay. México: Universidad Autónoma de México.

Guillén Galindo M. (1999). La distribución de competencias entre el Estado, las Comunidades Autónomas y las Entidades Locales. Especial referencia a la Comunidad Valenciana. En Actas del I Congreso Universitario de Turismo, celebrado los días 27 a 29 de Octubre de 1998 en Peñíscola, Castellón. (pp. 37-62). Valencia: Ed. Tirant lo Blanch.

Güidi, G. (2014). Características y alcances de la actividad turística y su regulación. Las leyes nacionales de turismo en el Digesto Jurídico Argentino. En Brena, R. G. (Editor). Digesto Jurídico Argentino Comentado, $1^{\underline{a}}$ Edición (pp. 803-870). Ciudad Autónoma de Buenos Aires: La Ley S.A.E. e I.

Montaner Montejano, J. (2002). Política y relaciones turísticas internacionales. Barcelona: Editorial Ariel Turismo.

Peña Miranda, D. (2009). Los instrumentos legales de la política turística como base para un turismo responsable y sostenible en Latinoamérica; análisis para Colombia, Perú, México y Honduras. Revista de Análisis Turístico 8, 2ํsemestre, 33-43. 
Pérez Guerra, R. y Ceballos Martín, M. (2009). La configuración del derecho del turismo autonómico español en el ordenamiento jurídico administrativo-constitucional". Separata de la Revista Aragonesa de Administración Pública 35, 455-515.

Perotti, D. A. (2011). Habilitación constitucional para la Integración Comunitaria. Estudio sobre los Estados del Mercosur. Lisboa: Editorial Juruá.

Santana, A. (2008). Antropología y turismo. ¿Nuevas hordas, viejas culturas?. L’Hospitalet de Llobregat: Editorial Ariel S.A.

Sentencia del Tribunal Constitucional Español 123/1984 de 18 de Diciembre de 1984 (Fundamento Jurídico 3.), publicada en el Boletín Oficial del Estado núm. 10 de 11 de enero de 1985)

Urdaneta Salinas, C. (2002). Cronología de la legislación turística venezolana. Revista Anuario 25, Instituto de Derecho Comparado de la Facultad de Ciencias Jurídicas y Políticas de la Universidad de Carabobo, Venezuela. Recuperado de http://servicio.bc.uc.edu.ve/derecho/revista/

Viver Pi-Sunyer, C. (1989). Materias competenciales y Tribunal Constitucional. La delimitación de los ámbitos materiales de las competencias en la jurisprudencia constitucional. Barcelona: Editorial Ariel S.A. 